\title{
Repeated measurements of tibia lead concentrations by in vivo $x$ ray fluorescence in occupational exposure
}

\author{
Rosemary Armstrong, David R Chettle, Malcolm C Scott, Lillian J Somervaille, \\ Matthew Pendlington
}

\begin{abstract}
A group of workers occupationally exposed to lead have had measurements of their tibia lead concentrations made on two occasions separated by five years; on the second occasion calcaneus lead concentrations were also measured. The results serve to confirm the reliability of the measurement technique and to illustrate the improved precision achieved through technical improvements. More importantly, the relation between tibia lead concentration and cumulative blood lead found in this longitudinal study was entirely consistent with that previously reported, which had been based on cross sectional studies. Furthermore, the relation between lead concentrations in the tibia and in calcaneus found here was similar to that previously found in a larger cross sectional survey. It is concluded that this technique of measuring bone lead concentrations non-invasively is likely to be used increasingly as a biological monitor of cumulative exposure to lead.
\end{abstract}

Occupational exposure to lead is routinely monitored by regular measurements of lead concentrations in blood. This reflects exposure over a period of a few weeks before sampling. ${ }^{1}$ The development of in vivo $x$ ray fluorescence techniques for measurements of lead concentrations in bone, however, provided a biological monitoring technique for skeletal burden..$^{23}$ An earlier report, based on cross sectional surveys of three factories, showed that in vivo tibia lead measurements made in this way provided an index of cumulative occupational exposure to lead. ${ }^{4}$

Medical Physics Group, School of Physics and Space Research, University of Birmingham, Birmingham B15 2TT, UK

R Armstrong, D R Chettle, M C Scott, L J Somervaille

Present address: RRPPS, PO Box 803, Edgbaston, Birmingham B15 2TB

D R Chettle

63 Bloxwich Road South, Willenhall, West Midlands WV13 1AZ

$M$ Pendlington
It has now been possible to repeat the first of these surveys, originally undertaken in 1983, after an interval of five years. Although the number of exposed people was small, it has been possible to examine the change in tibia lead concentration in the intervening time and to compare this with the results of blood lead measurements made during the same period. Also, it was possible to retrieve blood lead monitoring records for this workforce that had not been presented in the previous report, and to construct a blood lead index from these. Lastly, measurements of lead concentrations were made in calcaneus as well as in the tibia as reported previously. Thus the original work, based on cross sectional surveys, has been supplemented and compared with a small scale longitudinal data set.

\section{Population and methods}

In the original set of measurements 15 members of the workforce of a precious metal refiner had been examined, one in our laboratory and the remainder on site at the factory. Of these, only five were still employed at the factory; these, and four other members of the workforce, not previously examined, had bone lead measurements. Attempts were made to contact subjects who had left the factory and two of them responded to an invitation to visit our laboratory for follow up measurements. Thus repeated measurements were made on seven people.

Lead concentrations in the tibia and calcaneus were measured simultaneously using two independent sets of ${ }^{109} \mathrm{Cd}$ excited $\mathrm{K} x$ ray fluorescence apparatus. $^{3}$

The blood lead records for the period between the two sets of measurements were made available to us, as were all the monitoring data on the 19 people who had participated in one or other of the two sets of measurements.

The records for the interval between measurements were complete with the exception that the two people who had left the factory had not been regularly monitored after they had ceased occupational exposure in 1986. Integrated blood lead indices were calculated for all 19 people in the manner previously described. ${ }^{4}$ For the two people who had left the factory, environmental exposure 
between the two bone lead measurements will have been much less than their occupational exposure in the intervening time, so their blood lead indices covered only the period of their occupational exposure. Blood lead concentrations associated with the United Kingdom urban environment are likely to be in the range $10-15 \mu \mathrm{g} \mathrm{dl}^{-1}$, ${ }^{4}$ and these people had ceased occupational exposure for two years; their average blood lead concentrations while they were at work had been 59 and $65 \mu \mathrm{g} \mathrm{dl}^{-1}$ and they had worked for 12 and 15 years respectively. Cumulative indices were calculated for the time of the original measurements (1983) and for the repeat measurements in 1988. In reconstructing the records it was necessary with certain subjects to extrapolate to times before regular blood lead monitoring had been introduced, and for some cases a substantial interpolation of appreciably greater than one year had to be made because a subject had missed one or more of the monitoring sessions. Thus the blood lead indices were based partly on direct measurement and partly on estimates; for five of the 19 people the estimated portion exceeded $50 \%$ of the total cumulative blood lead index.

\section{Results}

For the tibia lead measurements made in 1983 the average uncertainty in a single measurement was $9.3 \mu \mathrm{g} \mathrm{g}$ bone mineral ${ }^{-1}$ and the mean lead concentration in the 15 people seen then was $54.4 \mu \mathrm{g}$ g bone mineral ${ }^{-1}$. In 1988 the average uncertainty in a tibia measurement was $4.9 \mu \mathrm{g} \mathrm{g}$ bone mineral ${ }^{-1}$ and the mean tibia lead concentration was $44 \cdot 2 \mu \mathrm{g}$ g bone mineral ${ }^{-1}$ in the 11 people examined at this time. The average uncertainty for calcaneus lead concentration was $10.3 \mu \mathrm{g} \mathrm{g}$ bone mineral ${ }^{-1}$ and the mean calcaneus lead concentration was $110.7 \mu \mathrm{g} \mathrm{g}$ bone mineral ${ }^{-1}$ in these 11 people.

For the seven people common to both groups, mean tibia lead concentration was $49.0 \mu \mathrm{g}$ g bone mineral ${ }^{-1}$ in 1983 and $58.7 \mu \mathrm{g} \mathrm{g}$ bone mineral ${ }^{-1}$ in 1988. The change in the mean was thus $+9 \cdot 7$ (SD 3.9) $\mu \mathrm{g} \mathrm{g}$ bone mineral ${ }^{-1}$; the uncertainty quoted being based only on a combination of the measurement counting statistics for the two occasions. The mean change in cumulative blood lead index between the two bone lead measurements was $186 \cdot 4 \mu \mathrm{g} \mathrm{y} \mathrm{dl}^{-1}$. No significant correlation was found between the changes in tibia lead concentrations and blood lead index, which was not surprising given both the large individual errors, particularly in the tibia measurements made in 1983, and the small number of people concerned. The ratio of change in tibia lead concentration to change in blood lead index was 0.052 (SD 0.021), which can be compared with the slope of tibia lead concentration $v$ blood lead index previously seen in cross sectional studies $(0.060$ (SD 0.005)) and 0.050 (SD 0.003) respectively in factories $\mathrm{B}$ and $\mathrm{C}^{4}$ and with the analogous cross sectional relation seen in this factory both for the 1983 measurements $(0 \cdot 103$ (SD 0.016)) and the 1988 measurements $(0 \cdot 102$ (SD 0.015)). The table summarises these relations.

In the 11 subjects measured in 1988 calcaneus lead concentrations correlated significantly with tibia lead concentrations $(r=0.792, p<0.005)$. The structural relation ${ }^{4}$ was given by:

$$
\text { tibia }=0.498 \times \text { calcaneus }-10.97
$$

This is similar to the relation seen in a larger cross sectional survey ${ }^{6}$-namely,

$$
\text { tibia }=0.400 \times \text { calcaneus }+5.88
$$

The mean and SD of the standardised difference between the tibia lead measurements $(\Delta)$ were assessed and found to be 0.962 (SD 0.902). Where

$$
\Delta=\frac{\text { tibia }_{1988}-\text { tibia }_{1983}}{\left(\sigma_{1988}^{2}+\sigma_{1983}^{2}\right)^{\frac{1}{2}}}
$$

$\Delta$ would have an expected mean of 0 and an expected SD of 1 if no change occurred in tibia lead concentration and if all the variance were accounted for. This both confirms the significant increase in bone lead concentration between the two measurements and shows that no evidence existed for increased variance other than that associated with measurement counting statistics.

The reasons for the improvement in precision in tibia lead measurements, from SD 9.3 to SD $4.9 \mu \mathrm{g} \mathrm{g}$ bone mineral ${ }^{-1}$, have been discussed elsewhere, ${ }^{7}$ this study does, however, confirm that significant improvement. Ii is also noteworthy that the relative precision of the calcaneus measurement (10.3/110.7),

\begin{tabular}{|c|c|c|c|c|c|}
\hline Group & 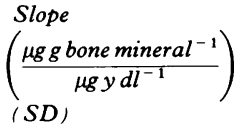 & $\begin{array}{l}\text { Intercept } \\
\left.\text { ( } \mu g g \text { gone mineral }{ }^{-1}\right) \\
(S D)\end{array}$ & No & $r$ & p Value \\
\hline $\begin{array}{l}\text { Factory B } \\
\text { Factory C } \\
\text { This factory (1983) } \\
\text { This factory (1988) }\end{array}$ & $\begin{array}{l}0.060(0.005) \\
0.050(0.003) \\
0.103(0.016) \\
0.102(0.015)\end{array}$ & $\begin{array}{l}-1.824(3.122) \\
+7.802(2.564) \\
+2.945(9.621) \\
-1.940(8 \cdot 214)\end{array}$ & $\begin{array}{l}88 \\
87 \\
15 \\
11\end{array}$ & $\begin{array}{l}0 \cdot 82 \\
0 \cdot 86 \\
0 \cdot 87 \\
0 \cdot 91\end{array}$ & $\begin{array}{l}<0.001 \\
<0.001 \\
<0.001 \\
<0.001\end{array}$ \\
\hline
\end{tabular}
is comparable with that of the tibia measurements,

Table Relation between tibia lead and cumulative blood lead index 
$(4 \cdot 9 / 44 \cdot 2)$. This is because, in these circumstances of occupational lead exposure, the calcaneus lead concentration is roughly twice that in the tibia when concentrations are expressed with respect to mass of bone mineral.

\section{Discussion}

This small study, comprising repeated in vivo bone lead measurements, serves to highlight two points. The first is the reliability of the measurement technique, which was established by the fact that the variance in the difference between tibia lead measurements separated by about five years was all accounted for by the known measurement variance associated with counting statistics. This reliability was further substantiated by the similarity in the relation between calcaneus lead and tibia lead concentrations and that seen in a separate larger cross sectional survey. ${ }^{6}$

A second point of interest is the relation between tibia lead concentration and the cumulative blood lead index. This had previously been determined on the basis of cross sectional studies ${ }^{4}$ so it is particularly encouraging to see that the ratio of changes in tibia lead concentration to cumulative blood lead index was consistent with the slopes of the relations, both those previously reported and those arising from the present data set (table). The limited longitudinal data thus far available preclude a very precise analysis of this relation as yet, but the results of this small scale study do serve both to confirm the robustness of these in vivo bone lead measurements and to underline their application as a biological monitor of cumulative exposure to lead.
We are grateful to members of the workforce of John Betts Refiners Ltd for their willing cooperation in this study, and particularly to $\mathrm{Mr} \mathrm{M}$ S Boswell-Munday for helping us to organise the work.

The present study is part of a programme of research supported by the UK Health and Safety Executive; this support is gratefully acknowledged as is the active collaboration provided by members of staff of the HSE Occupational Hygiene and Medicine Laboratories.

Requests for reprints to: Malcolm C Scott, Medical Physics Group, School of Physics and Space Research, University of Birmingham, Birmingham B15 2TT, UK.

1 Rabinowitz MB, Wetherill GW, Kopple JD. Kinetic analysis of lead metabolism in healthy humans. J Clin Invest 1976;58: 260-70.

2 Ahlgren L, Lidén K, Mattsson S, Tejning S. X-ray fluorescence analysis of lead in human skeleton in vivo. Scand $J$ Work Environ Health 1976;2:82-6.

3 Somervaille LJ, Chettle DR, Scott MC. In vivo measurement of lead in bone using x-ray fluorescence. Phys Med Biol 1985;30: 929-43.

4 Somervaille LJ, Chettle DR, Scott MC, et al. In vivo tibia lead measurements as an index of cumulative exposure in occupationally exposed subjects. $\mathrm{Br} J$ Ind Med 1988;45: 174-81.

5 Quenouille MH. Associated measurements. London: Butterworths, 1952;71.

6 Somervaille LJ, Nilsson U, Chettle DR, et al. In vivo measurements of bone lead-a comparison of two x-ray fluorescence techniques used at three different bone sites. Phys Med Biol 1989;34:1833-45.

7 Chettle DR, Scott MC, Somervaille LJ. Improvements in the precision of in vivo bone lead measurements. Phys Med Biol 1989;34:1295-300.

Accepted 13 May 1991 